\title{
Carreira, família e a dialógica do assujeitamento: 0 discurso vigente em uma revista popular de negócios
}

\author{
Career, family, and the dialogics of subjection: the effective discourse in a popular \\ business magazine
}

\author{
Andrea Poleto Oltramari ${ }^{1}$ \\ Bibianade Paula Friderichs ${ }^{2}$ \\ Denize Grzybovski
}

\section{Resumo}

Há uma série de pesquisas acadêmicas sobre assuntos relacionados à gestão em mídias populares de negócios que possibilitam uma visão do modelo de gestão disseminado na atualidade. O objetivo deste artigo é compreender, por meio do estudo da discursividade em nível verbal e não verbal, como tal modelo gerencial, no que concerne às relações entre carreira e família, revela-se na revista Você $S / A$. A abordagem teórica do modelo gerencialista é de Vicent de Gaulejac, para quem os princípios da vida são substituídos por princípios interiorizados pela lógica da organização, tornando o sujeito pronto a tudo para ter sucesso. A sustentação metodológica é construída com base nos pressupostos da semiologia barthesiana, por intermédio de três categorias a priori: discurso, estereótipo e mito. Elas estão organizadas em uma disposição que contempla a discursividade, transitando dos seus aspectos mais concretos para os mais abstratos, com a finalidade de facilitar a leitura do nosso objeto. Os resultados indicam que a principal oferta feita ao leitor manifesta-se por meio de uma série de receituários no que concerne à solução dos dilemas relativos à família e/ou carreira, cuja decisão de prioridade, de um lado, fica a cargo do empregado, e do outro, já está predeterminada pela condição de seu assujeitamento.

Palavras-chave: Carreira. Família. Gestão gerencialista. Discurso editorial.

\begin{abstract}
There are a number of academic researches on issues related to management in popular business media that provide a view of the management model promoted nowadays. The purpose of this article is understanding, through the study of discursivity at the verbal and nonverbal levels, how such management model, regarding the relations between career and family, reveals itself in the magazine Você $S / A$. The theoretical approach to the managerial model is that provided by Vicent de Gaujelac, for whom life principles are replaced by principles embodied through the rationale of the organization, making the subject ready to anything to succeed. The methodological support is constructed having the
\end{abstract}

Artigo submetido em 19 de julho de 2013 e aceito para publicação em 10 de janeiro de 2014.

${ }^{1}$ Doutora em administração pela Universidade Federal do Rio Grande do Sul; Professora titular da Universidade de Passo Fundo/UPF. Endereço: Rua Capitão Araújo, 511, Apto. 1102, CEP 99010-200, Passo Fundo - RS, Brasil. E-mail: andreaoltr@gmail.com

${ }^{2}$ Doutora em comunicação pela Pontifícia Universidade Católica do Rio Grande do Sul; Professora da Universidade de Passo Fundo/UPF. Endereço: Rua Capitão Eleutério, 213, Apto. 301, CEP 99010060, Passo Fundo - RS, Brasil. E-mail: bibiana@upf.br

${ }^{3}$ Doutora em administração pela Universidade Federal de Lavras/UFLA; Professora titular da Universidade de Passo Fundo/UPF; Professora Convidada no Programa Stricto Sensu em Desenvolvimento da Universidade Regional do Noroeste do Estado do Rio Grande do Sul/UNIJUÍ. Endereço: Rua Uruguai, 1391, Apto. 402, Centro, CEP 99010-111, Passo Fundo - RS, Brasil. E-mail: gdenize@upf.br 
assumptions of Barthes' semiology as a basis, by means of three a priori categories: discourse, stereotype, and myth. They are arranged in order to address discursivity, moving from their more concrete to their more abstract aspects, with the purpose to make the reading of our object easier. The results indicate that the main offer made to the reader is manifested through a series of prescriptions with regard to the solution of dilemmas related to family and/or career, whose decision in terms of priority, on the one hand, is up to the employee, and on the other hand, is already predetermined by the status of her/his subjection.

Keywords: Career. Family. Managerialist management. Editorial discourse.

\section{Introdução}

Há uma série de pesquisas acadêmicas sobre assuntos relacionados à gestão em mídias populares de negócios, especialmente em revistas, e que vem possibilitando uma visão do discurso gerencial disseminado na atualidade, de "um ideal de indivíduo que se comporta racionalmente e que é capaz de alcançar sempre mais [...], como se ele próprio fosse uma empresa privada (MORAES, 2012, p. 287)." Segundo Wood Jr. e Paula (2002), essas publicações objetivam serializar e modelar trabalhadores de acordo com as necessidades do mercado. Para isso, mais do que informações objetivas sobre o contexto social do mundo dos negócios, a literatura pop management fornece aos leitores instruções sobre como ser ou como atuar, caso algum deles deseje tornar-se rapidamente um “empresário responsável por si mesmo” (GAULEJAC, 2007).

Esse discurso editorial intensificou a mercantilização do ensino superior em administração e das práticas de gestão, gerando críticas a um tipo de literatura descartável (CARVALHO, CARVALHO e BEZERRA, 2010) até mesmo entre os estudantes, pela dificuldade em distinguir os gêneros literários "autoajuda", esotéricos e pop management (CARVALHO, CARVALHO e BEZERRA, 2010). Contudo, é preciso lembrar que a literatura pop management surgiu na década de 1980, momento em que o ambiente de negócios era marcado por forte turbulência e competição, o qual requeria uma literatura pautada por temas como ansiedades e dilemas dos profissionais de administração sobre suas carreiras (WOOD JR e PAULA, 2002). Hoje, o contexto é outro, a velocidade impressa pelas tecnologias de informação e de comunicação (TICs) e a presença de nativos digitais (VEEN e VRAKKING, 2009) no mercado de trabalho desafiam os editores e o ensino da administração no Brasil.

Num mundo pautado pela velocidade, pela fluidez e pela efemeridade das relações, sejam elas profissionais ou pessoais, Bauman (2001) lembra que não há tempo a perder com o lento processo de construção e de reconhecimento da identidade (pessoal/profissional), tanto por parte da empresa quanto do sujeito. É preciso, portanto, forjá-la para que seja uma resposta imediata à determinada demanda, exibindo as qualificações e o perfil esperado pelo outro (empresa/gestor/amigos) (BAUMAN, 2001). Sob o ponto de vista do profissional, nos dias que correm agravados pela redução dos postos de trabalho e pela crescente automação dos processos de produção, "dicas, compradas na banca mais próxima", de como entrar e se manter no mercado de trabalho, parecem ser um apelo irresistível, a garantia de um presente promissor. Mas, sob outra perspectiva, a epistêmica, a do pesquisador, estes mesmos conteúdos podem ter diferentes significados e evidenciar as características de uma gestão gerencialista (GAULEJAC, 2007; SANTOS, GRISCI, TEIXEIRA et al, 2012), que busca, também por meio do discurso midiático, consolidar-se como modelo predominante. Este, por sua vez, pode gerar patologias no comportamento humano, em especial a quantofrenia, "que consiste em querer traduzir sistematicamente os fenômenos sociais e humanos em linguagem matemática" (GAULEJAC, 2007, p. 94), como se a experiência humana pudesse ser traduzida em cálculo (MORAES, 2012).

Esse é um dos aportes teóricos que sustenta o presente artigo. Seu esforço é de compreender como os fundamentos da gestão gerencialista, na concepção de Gaulejac (2007), se revelam na revista Você $S / A$, especialmente em uma edição temática "Decisão Difícil" (março, 2013), que permite explorar o tema "carreira e família". É importante ressaltar que outras pesquisas semelhantes já foram realizadas 
considerando diferentes temas, tais como: carreira e sucesso (SANTOS, GRISCI, TEIXEIRA et al., 2012); representações do corpo (ECCEL, GRISCI e TONON, 2010); sofrimento psíquico no trabalho (FLACH, GRISCI, SILVA et al., 2009) e sobre o tempo e espaço do trabalho (FREZZA, GRISCI e KESSLER, 2009). Optou-se pela análise da temática carreira e família, porque tais estudos têm sido recorrentes na academia e vêm apresentando os dilemas pessoais relativos à tentativa de equilíbrio entre os espaços público (da carreira) e privado (da família). Não obstante, mesmo que a existência de dilemas não se mostre inédita na academia, em revistas populares de negócios, esse olhar se mostra ainda escasso. Agrava-se o fato de que a tiragem da edição da revista em análise foi de 175.576 mil exemplares, totalizando uma média de 513.518 mil leitores (PUBLIABRIL, 2013). Assim, a escolha do periódico e da edição se justifica pela expressiva circulação no Brasil e pela forma como o seu conteúdo é discutido entre os profissionais, no cotidiano, considerando: (a) o estresse como uma decorrência "natural" da busca legítima por um lugar de excelência e autorrealização, e; (b) a pressão advinda do mundo empresarial como um estímulo à construção de uma "subjetividade fluída" (GAULEJAC, 2007, p. 187), a qual provoca uma crise simbólica que retira o significado da própria vida (GAULEJAC, 2007; MORAES, 2012).

Aliás, é justamente a partir deste último aspecto, pertinente à efetivação de um campo (o empresarial), e de uma cultura (a gerencialista), por meio de uma estrutura simbólica, que podemos observar a tensão entre a subjetividade e a linguagem; ou, para além disso, o relevante papel dos textos em circulação, e os discursos em que se constituem, como articuladores de modelos de comportamento e identidades. Isso porque "não existe sujeito fora da linguagem".

Esta pequena frase, embora inequívoca, abriga a extraordinária esfinge em torno da qual nos debatemos em inúmeras ciências. Sua brevidade também indicia a energia do signo, que, a partir de uma relação dialética entre forma e conteúdo, abriga, mesmo em acanhadas porções de linguagem, sentidos imprevisíveis, fugidios e múltiplos. Citado por Roland Barthes (1988, p. 106), o trecho referido aciona no ensaio A paz cultural essa trama de perspectivas inquietantes acerca dos descaminhos do discurso na construção da realidade com a qual está reincidentemente conectado, menos como um sumidouro e mais como um mapa sem mina, sem "xis", uma rota abalada, onde a significação pode se dispersar. Não há uma imposição que determine o fim do sentido, seu fechamento, um significado único e acabado para determinado signo, por menor que seja o espaço que ocupa no texto - evidência peremptória diante da complexidade do papel que os falares ocupam na configuração do real.

Para o autor, o homem só se constitui na linguagem, a partir do atravessamento dos signos, que estão por todos os lados e cujo "poder é infinito" (1971, p. 270). Ela é a disparadora das dinâmicas instaladas no cotidiano e, mais do que isso, fonte de transformação do real palpável. A linguagem é a forma de organizar e compreender o mundo que nos rodeia, e os discursos, através dela estruturados, expressam as ideias de determinados sujeitos ou grupos sobre a realidade - na medida em que tentam defini-la ou explicá-la -, a consciência que esses indivíduos possuem de si, do outro e sobre o ambiente em que vivem. Por isso, Barthes (1971) destaca que os discursos em circulação pelo cotidiano social são espaços de realização da sua subjetividade, não apenas porque o homem constrói este ou aquele significado na medida em que é atravessado pelos signos que compõem esta linguagem, mas pelo jogo próprio do trabalho de significação, que invariavelmente o coloca diante do caleidoscópio da alteridade.

Sob esta perspectiva, Friderichs (2010) lembra que a linguagem é produto de um contrato coletivo e diacrônico e está revestida de um caráter público. Aliás, caráter esse particularizado na contemporaneidade, tempo em que as relações possíveis entre a realidade, a linguagem e o sentido parecem ter se tornado alvo de uma dinâmica de comunicação midiatizada. Na sociedade da informação e talvez, também, do conhecimento, os meios multiplicaram-se como os principais canais de produção e distribuição de bens culturais (KELNER, 2001), dominando os espaços de alteridade e de troca. 
A mídia tornou-se, assim, um lugar privilegiado do discurso em suas diferentes manifestações, e os formatos jornalísticos, consequentemente, formas de fala, textos públicos, que circulam pelo ambiente social, provocam certo movimento. Essa é a matéria-prima para as nossas ${ }^{4}$ reflexões, pois, através deles (dos discursos midiáticos), o homem pode reprisar ou construir novos sentidos sobre a realidade, conhecer sua própria imagem, localizar-se como sujeito histórico e transformar as condições do cenário social com o qual está comprometido (FRIDERICHS, 2010; RAMOS, 2012). Isso porque ler é também escrever, uma vez que, diante dos significantes oferecidos à fruição durante a leitura, é o leitor quem produz em si, concomitantemente, outro texto no qual pode ressignificar o mundo ao seu redor e relacionar-se, de outros e inusitados modos, com ele (BARTHES, 1988).

Entretanto, para alguns autores (SODRÉ, 2002; RAMOS, 2001; DEBORD, 1997), esta mesma mídia, cujo potencial discursivo revela possibilidades de intervenção dos sujeitos diante da realidade, é sensacionalista; um agente de interpelação que expõe os conflitos do cotidiano social, reduzidos e esvaziados de historicidade, ao mesmo tempo que apresenta soluções e/ou respostas pré-fabricadas e instantâneas para eles.

Dentre os autores que se debruçam sobre essa questão está Barthes (1971). Uma das principais preocupações do autor refere-se ao papel da fala na constituição das relações sociais, mais especificamente da língua. Não de modo restrito, ou seja, relacionado à língua escrita, mas às estruturas linguísticas às quais devemos submeter nosso pensamento para expressá-lo, e, além delas, à dimensão translinguística que incide sobre essa dinâmica. De acordo com suas reflexões, de certa forma, somos aprisionados por determinadas estruturas, algumas delas naturalizadas pela mídia; nem sempre conseguimos fazer rupturas em favor da polissemia do texto.

A gestão gerencialista, por exemplo, como uma dimensão translinguística (que está fora das regras gramaticais), faz interface com a linguagem e, de certa forma, pressiona o sujeito a adotar certas estruturas de sentido ao construir sua fala. A seguir, apresentam-se discussões acerca da gestão gerencialista e a produção da subjetividade na mídia popular de negócios.

Assim, o presente artigo foi organizado da seguinte forma: inicialmente, aborda discussões teóricas acerca das relações entre gestão gerencialista e mídia popular de negócios, ao projeto de cada indivíduo tornar-se gestor de sua própria vida, capaz de fixar objetivos, tornar seu tempo rentável. Ainda, nesta etapa, faz-se uma reflexão sobre os dilemas contemporâneos, especialmente no que se refere à construção da carreira e seus reflexos nas relações familiares. Na seção seguinte são apresentados os procedimentos de investigação. Na terceira seção são apresentados os resultados do estudo, a análise e a interpretação dos dados. Na última seção, as conclusões.

\section{Gestão, Subjetividade e Mídia Popular de Negócios: o modelo gerencialista}

O culto à empresa, que teve seu ápice nos anos 1980, provocou várias transformações na sociedade, através da difusão massiva dos discursos e práticas de gestão, os quais contribuíram para a formação de uma sociedade managerial, como caracteriza Chanlat (2000). Nesta sociedade, o sistema de descrição, explicação e interpretação do mundo passou a ser feito a partir de categorias da gestão, com o uso frequente da linguagem administrativa e a reprise dos signos de produtividade e performance. Desta forma, observou-se uma racionalização de todas as esferas da vida social (WEBER, 2004) e pessoal, onde os espaços sociais, como casa, escola, universidade, hospital, passaram a ser administrados como empresas, e as pessoas

\footnotetext{
${ }^{4}$ Utilizamos a primeira pessoa do plural neste artigo considerando os aspectos evidenciados pelo método dialético histórico-estrutural (DHE), que nos permitem compreender o real, como algo histórico e socialmente constituído. Vivemos em permanente relação com o outro e acreditamos que parte do fazer científico liga-se a um questionamento acerca do lugar de onde falamos, pois não é possível separar a objetividade da ciência da subjetividade do pesquisador.
} 
assumiram um comportamento pró-competitividade orientado pela lógica do ganha-ganha. A ascensão da racionalidade na sociedade foi fortalecida pelos processos de globalização dos mercados e da reengenharia de processos, que transformaram os locais de trabalho em ambientes de livre mercado, estimulando a competitividade e transformando-se em lugar propício ao crescimento individual, ou seja, numa "gestão racional de si mesmo" (MORAES, 2012). O efeito a curto prazo foi a melhoria da competitividade dos países que adotaram tal orientação, com o aumento das doenças psicossomáticas decorrentes do trabalho do indivíduo que acredita ser capaz de alcançar sempre mais; é a exigência da excelência escondida sob o conceito de qualidade (GAULEJAC, 2007).

A orientação da gestão também se modificou, e Gaulejac (2007) propõe a substituição da "gestão de recursos humanos" pela "gestão humana de recursos" (p. 145), por acreditar que um outro mundo é possível. Sob esta perspectiva, o operário deixa de ser considerado apenas capaz de produzir bens materiais (um recurso) para ser considerado uma força produtiva orientada pela psique para capitalização das empresas (GAULEJAC, 2007) e produtor de bens intangíveis, tais como sentimentos de confiança, segurança e conforto em relação a seus consumidores, mobilizando características que lhes são inerentes, como inteligência, criatividade, tomada de decisão e capacidade de relacionamento.

Assim, com o intuito de manter-se "na mira" das grandes corporações, os indivíduos buscam, nas revistas de negócios, os meios de tornarem-se atraentes ao mercado de trabalho, pois "o novo formato de gestão propõe regras que excitam o ego, prometendo-lhe satisfação do desejo sem limites" (MORAES, 2012, p. 288). E essas revistas, por sua vez, através das reportagens, entrevistas e publicidade, indicam modos de ser, vestir e agir, tentando garantir que os indivíduos se comportem da forma esperada pelas empresas. Isso porque, nas palavras de Gaulejac (2007), é o "gosto humano por empreender, o desejo de progredir, a celebração do mérito ou o culto da qualidade" (p. 81) - fundamentos orientadores da nova gestão com reforço narcísico no comportamento - que reitera o discurso de que o crescimento pessoal do indivíduo corresponde ao crescimento da empresa.

A mídia, tal como existe hoje em dia, tem um papel de destaque na produção de "subjetividades fluídas" (GAULEJAC, 2007, p. 187), visto que estas são essencialmente fabricadas e modeladas no registro do social, por meio da apropriação feita pelos indivíduos de certas formas simbólicas que são distribuídas pelos discursos em circulação. Discursos estes que, ao associarem-se às plataformas midiáticas, ocupam lugar privilegiado de abrangência e eco, reprisando determinadas ideias de mundo via destaque e repetição de figuras de linguagem, como destaca Barthes (2001a).

Entretanto, esses discursos (que se estruturam em textos, no sentido amplo do termo), não têm uma verdade escondida, sua significação não está a priori determinada, nem acabada, como um circuito fechado, esperando para ser acessado. Barthes (1988) lembra que a linguagem, por si só, não guarda uma significação, mas que ela se constitui como uma forma vazia que é preenchida pelos sentidos que somos capazes de construir a partir da nossa cultura (formada pelo atravessamento de todos os outros textos e discursos com os quais já nos deparamos e a nossa capacidade de lê-los, colocá-los em diálogo, questioná-los, convertê-los em experiência). Portanto, não é ela (a linguagem) que produz subjetividade, mas sim o homem, que o faz através dela.

Nesse sentido, segundo Tiburi (2011), a mídia tem papel de subjetivar o indivíduo, referindo-se a retirar possibilidades autênticas de relacionamentos, liberdade, outrora conquistada pelos sujeitos. É uma subjetividade capitalista, como afirma Guatarri e Rolnik (2005):

O que é produzido pela subjetividade capitalística, o que nos chega através da mídia, da família, enfim, de todos os equipamentos que nos rodeiam, não são apenas ideias; não é a transmissão de significações através de enunciados significantes; nem são os modelos de identidade [...]. São, mais essencialmente, sistemas de conexão direta, entre, de um lado, as grandes máquinas produtoras de controle social e, de outro, as instâncias psíquicas, a maneira de perceber o mundo (p. 67). 
Assim, em sistemas tradicionais, a subjetividade é fabricada por máquinas mais territorializadas, na escala de uma etnia, de uma corporação profissional, de uma casta. Já no sistema capitalístico, a produção é industrial e se dá em escala internacional (GUATTARI e ROLNIK, 2005), e que está ligada a certo grupo de corporações.

Na interpretação de Pagès, Bonetti, Gaulejacet al. (1993), essas corporações dizem respeito a construções sociais de sedução ambígua na qual os indivíduos têm de internalizar as regras que compõem uma "estrutura abstrata", o jogo. Essas transmitem a impressão de liberdade e independência, mas que é, na verdade, uma "autonomia controlada" (PAGÈS, BONETTI, GAULEJAC et al., 1993,). Os detentores de poder, numa sociedade capitalística, produzem uma subjetividade inconsciente. Por exemplo, acredita-se que aquele que não dedicar muitas horas de trabalho não será reconhecido pelo trabalho realizado; que aquele que não abrir mão de sua vida pessoal em prol da empresa não será recompensado. Dessa forma, aos poucos, a subjetividade dos indivíduos é desenvolvida, ou forjada (PAGÈS, BONETTI, GAULEJAC et al., 1993), com base no sistema de submissão dissimulado, de assujeitamento, e, então, os empregados se tornam, cada vez mais, seres de fácil manipulação.

Sobre o sentido de assujeitamento, Strogenski (2003) explica:

Os analistas franceses defendem a segunda ideia, a de que o sujeito, ao passar de um ambiente para outro, assume os discursos institucionais possíveis conforme o seu trânsito. A esse processo de adaptação discursiva dá-se o nome de assujeitamento. Um sujeito assujeitado é aquele que se apropria de um discurso preexistente e faz uso dele a partir de regras também preexistentes. A consequência dessa concepção acaba sendo a de se supor que não existem discursos originais ou textos individuais.

Talvez por isso, Bauman (2005) se posiciona de forma crítica diante do contexto atual, no qual a modernização, a tecnologia e a globalização produziram um efeito colateral da construção da ordem e do progresso econômico: a produção do "refugo humano". Refugo humano (ou seres humanos refugados) constitui-se de indivíduos excessivos e redundantes ao planeta, ou seja, aqueles que não pertencem, que não se adaptam à nova ordem mundial, aqueles seres que estão sobrando, que não serão aproveitados pelas empresas, pelo Estado ou pelos próprios indivíduos.

Nas palavras do autor:

A produção de "refugo humano", ou, mais propriamente de seres humanos refugados (os "excessivos" e "redundantes", ou seja, os que não puderam ou não quiseram ser reconhecidos ou obter permissão para ficar), é um produto inevitável da modernização, e um acompanhante inseparável da modernidade. É um inescapável efeito colateral da construção da ordem (...) e do progresso econômico (que não pode ocorrer sem degradar e desvalorizar os modos anteriormente efetivos de "ganhar a vida" e que, portanto, não consegue senão privar seus praticantes meios de subsistência) (BAUMAN, 2005, p. 12).

Há sempre uma incerteza em relação ao futuro, as pessoas estão se tornado cada vez mais dispensáveis nos espaços físicos das organizações. Bauman (2001, p. 185) afirma que, no mundo do desemprego estrutural, ninguém pode se sentir verdadeiramente seguro. Não há muitas habilidades e experiências que, uma vez adquiridas, garantam que o emprego será oferecido, e que, uma vez oferecido, será durável. O mercado é volátil, instável, permeado de incertezas e por grande demanda de pessoas que nem sempre conseguem acompanhar essa dinâmica.

Segundo Lazzarato e Negri (2001), o trabalho do operário é um trabalho que implica sempre mais, em diversos níveis, capacidade de escolher entre algumas alternativas e, portanto, assumir a responsabilidade das 
decisões, dentre elas as que dizem respeito à família. Hoje, afirmam Lazzarato e Negri (2001), é a alma do operário que deve descer à oficina; é a sua personalidade e sua subjetividade que devem ser organizadas e comandadas. A qualidade e a quantidade do trabalho são organizadas em torno de sua imaterialidade.

A energia e tempo que antes eram despendidos com a família são transformados em capital (GAULEJAC, 2007). Para o indivíduo não restam mais nem tempo, nem força, nem disponibilidade para outra coisa, para encontrar "o sentido das palavras, o sentido de seu desejo, inventar uma existência para si mesmo" (GAULEJAC, 2007, p. 176). A gestão de si mesmo, no sentido de apresentar à prova sua rentabilidade, é o imperativo da contemporaneidade, e os dilemas que envolvem as decisões relativas aos caminhos a serem trilhados são complexos e delicados.

Conforme Pelbart (2000, p. 34):

Não se trata mais de adaptar-se ou obedecer a normas, mas de consumir serviços ofertados, que vão desde a dieta até a vida sexual e esportiva. O sujeito não mais se submete a regras, mas ele as investe, como se faz um investimento financeiro: ele quer fazer render, seu corpo, seu sexo, sua comida, ele investe nas mais diversas informações para se rentabilizar, para se fazer render, para fazer render o seu tempo.

É nesse sentido que os leitores das revistas populares de negócios consomem notícias e fazem uso delas para resolver seus dilemas sobre carreira e família.

\section{Dilemas, Carreira e Família}

Para Bauman (2007a), diante de um dilema "não há, então, uma boa escolha. Mas é exatamente isso que você é pressionado a fazer pelo ambiente em que tenta compor sua vida. Qualquer escolha que você faça, está arranjando confusão" (BAUMAN, 2007a, p. 142). A escolha, portanto, em uma situação de dilema, não é um exercício de liberdade. As pessoas não foram consultadas para que, antes da escolha, pudessem colocar em pauta as possibilidades dos caminhos a serem seguidos. A constante é que "a responsabilidade em resolver dilemas gerados por circunstâncias voláteis e constantemente instáveis é jogada sobre os ombros dos indivíduos - dos quais se espera que sejam 'free-chosers' e suportem plenamente as consequências de suas escolhas" (BAUMAN, 2007b, p. 10). Evidencia-se, dessa forma, o processo de escolha por que passam os indivíduos, inseridos em um ambiente em que as orientações de como agir e decidir já são pré-estabelecidas.

Associados aos dilemas, estão as formas de poder instituídos pelas organizações que adotam o modelo gerencialista (GAULEJAC, 2007). O "poder gerencialista" é, segundo o autor, um sistema de organização manifesta que se constitui em uma ideologia traduzida nas atividades humanas por indicadores claros de desempenho. O poder gerencialista constrói uma representação do capital humano como um recurso a serviço da empresa. Tal apropriação do indivíduo pela empresa produz subjetividades (GUATARRI e ROLNIK, 2005), que dizem respeito à glorificação da autonomia no trabalho, traduzidas por empreendedorismo ou agentes de sua própria vida; à obsessão por metas e à rentabilização de si e do corpo, à voracidade, como desejo impetuoso e insaciável (BLEICHMAR, 2008), dentre outros.

Nesse sentido, o poder gerencialista atua fortemente no comportamento dos profissionais em relação às escolhas em conteúdos sobre carreira e família. Ao normatizar comportamentos dos trabalhadores e incentivar a obsessão por metas, ele também atua sobre a intimidade privada da vida familiar, já que facilmente o trabalhador terá de adentrar além do horário contratual de trabalho para executá-lo. Essa "visão" conforta o sentimento de que o sucesso da empresa depende antes de tudo do comprometimento de todos (GAULEJAC, 2007, p. 85), inclusive membros da família. 
Não obstante, o que se tem percebido é uma gestão gerencialista de escolhas, tal como se apresenta em revistas populares de negócios. Gaulejac (2007) refere que a lógica do poder gerencialista transborda seu campo e coloniza toda a sociedade. Hoje, tudo é gerenciado - as cidades, as pessoas, as organizações, mas igualmente a família e as relações amorosas. Para o autor, é uma cultura do alto desempenho, que institui um clima de competição generalizada, e põe o mundo sob pressão. Isso acarreta de certa maneira o esgotamento profissional, o estresse e o sofrimento no trabalho, assim como na forma de conduzir a carreira e a família. Não é comum, entretanto, tais discussões virem à tona em revistas de negócios, especialmente porque, em geral, elas trazem uma noção de sucesso que se sobrepõe ao bem-estar familiar. Ituassu e Tonelli (2012, p. 210) corroboram com a noção de sucesso divulgada nas revistas de negócios e dizem que ela está "relacionada, predominantemente aos aspectos materiais, como renda e riqueza, além de elementos como reconhecimento, prestígio, status".

O desejo tanto do trabalhador quanto o de sua família por sucesso na carreira acarreta escolhas, tais como Oltramari (2010) apresenta. Em relato de familiares, a referida autora verificou que os mesmos preferem ficar mais tempo longe do executivo, mas terem mais possibilidades financeiras e manterem o status que a profissão permite. Tais escolhas se associam ao conceito de "vida líquida" a que Bauman (2007a) refere.

Pensar a relação entre carreira e família implica associá-la à sociedade líquido-moderna, apontada por Bauman (2009). A vida líquida é uma vida de consumo e, portanto, de descarte, de esquecimento, de substituição rápida e de laços frouxamente atados (ARGYRIS e SCHÖN, 1978; BAUMAN, 2004). A sociedade do descarte (HARVEY, 2004; BAUMAN, 2007a) significa mais que descartar; significa desvalorizar e/ou desconstruir estilos de vida, costumes, valores, relacionamentos, inclusive os familiares, especialmente se eles não permitirem a rentabilização daqueles membros que estão construindo a carreira. A "vida líquida", contida na "sociedade líquido-moderna", descrita por Bauman (2009), é uma vida precária, vivida em condições de incerteza constante, inconcebível numa proposta de desenvolvimento, e não "forjamento" da subjetividade dos indivíduos. Pelas suas condições de vida precária e pela supremacia do poder gerencialista, ocorre o assujeitamento.

Gaulejac (2007) aponta que "a própria família está impregnada pelo modelo gerencial e é encarregada de fabricar indivíduos produtivos. A cada período de seu desenvolvimento, o indivíduo deve estabelecer uma contabilidade existencial para demonstrar sua empregabilidade". Tal empregabilidade deve ser de todos os componentes da família, na qual os filhos são frutos produtivos que, futuramente, devem ser empregáveis na sociedade, com o amparo do investimento dos pais bem-sucedidos, feitos para com eles na infância, pois "se o filho não tem sucesso, é o balanço patrimonial da empresa familiar que se torna negativo. Eles são condenados ao sucesso para evitar a falência" (GAULEJAC, 2007, p.183). Desse modo, as exigências da sociedade líquido-moderna, apontadas por Bauman $(2007 \mathrm{a}, \mathrm{b})$, deixam as relações familiares mais frágeis, suscetíveis a riscos, estresse e ausência, assim como promove a emergência de dilemas nas escolhas na carreira. Enquanto isso, o gerenciamento pragmática os objetivos dos indivíduos para que eles se adaptem aos interesses econômicos das empresas, e a competição entre eles é instaurada como novo nexo de um mundo doente socialmente, que faz Gaulesa (2007) questionar as razões pelas quais a gestão atual, orientada pelo poder gerencia lista, provoca doença.

\section{Procedimentos de Investigação}

Considerando esse universo contextual, propomos, no presente artigo, o estudo da discursividade na edição de maio de 2011, da revista Você S/A, seção Agora, contemplando a produção de sentido em nível verbal e não verbal. A sustentação teórica será construída com base nos pressupostos de Roland Barthes, por intermédio de três categorias a priori: discurso; estereótipo e mito. Elas estão organizadas numa disposição que contempla a discursividade, transitando dos seus aspectos mais concretos para os mais abstratos, com a finalidade de facilitar a leitura do nosso objeto. 
Desse modo, partimos da categoria discurso, lugar onde se inscrevem acultura e seus interditos. Para Barthes (1978, p. 32), "todo o lençol do discurso é fixado por uma rede de regras, de constrangimentos, de opressões, de repressões, maciças ou tênues [...], sutis e agudas", onde o linguístico e o translinguístico perseveram. Nele, existimos como sujeitos da enunciação, apesar dos contornos plásticos que assumam. A subcategoria pirâmide, na concepção teórica de Genro Filho (1987) soma-se a essa preocupação no sentido de contemplar os diferentes planos de expressão deste tipo de narrativa.

Fundamentados nesses mesmos pressupostos, além da categoria já referida, estão os estereótipos e o mito. Para a semiologia, o primeiro pode ser aquele significado segundo cristalizado, seu grão, a ponta do iceberg mitológico. Seu princípio ativo está em transformar a História em natureza, como se a imagem evocasse naturalmente o conceito, dizendo-o sob a estrutura do que é obvio. Superar esta "necrose da linguagem" exige um abalo do sentido.

O mito também é, portanto, uma espécie de discurso, mas, de acordo com Barthes (2001), não é um discurso qualquer. Sua distinção no texto está caracterizada pela palavra repetida, pelo modo como apresenta determinada ideia, através da conotação. É uma fala historicamente descontextualizada, definida por sua intenção evidente. O mito nada esconde; ao contrário, aparece como uma confidência, uma cumplicidade, pois, se não percebêssemos essa intencionalidade, ele não poderia nos atingir. Trata-se de uma intenção naturalizada que nos interpela.

Mais do que isso, é uma ideia apropriada por um grupo específico e consumida por meio de um processo casual, aparentemente espontâneo e indiscutível. "A ubiquidade constitutiva da fala mítica vai apresentar-se, simultaneamente, como uma notificação e como uma constatação" (BARTHES, 2001a, p. 145). Assim, ele tem dupla função: faz compreender e impõe; trabalha com imagens pobres e incompletas, ignorando sua complexidade, onde o sentido está diminuído, simplificado. É uma fala despolitizada, que se concretiza na deformação do signo. Barthes (2001a) aponta para sete mitos discursivos: omissão da história (que elimina o contexto), identificação (figura do discurso que procura ignorar o outro e sua diferença), tautologia (solução mágica, escondida pela autoridade, para quem não encontra explicação), o ninismo (consiste em apontar dois caminhos e rejeitar ambos, favorecendo o continuísmo), a quantificação da qualidade (figura que justifica um pelo outro) e o mito da constatação (defende uma hierarquia inalterável das coisas e do mundo).

As reflexões propostas estarão ancoradas pelo método dialético histórico-estrutural (DHE) e na técnica metodológica da semiologia. Escolhemos a DHE, porque o método não tem o objetivo de fornecer respostas prontas para tudo, mas nos permite compreender o real como algo histórico e socialmente constituído. Para isso, observa as condições objetivas e subjetivas da realidade, de forma que podemos delinear o cenário onde nos encontramos imersos ao mesmo tempo em que procuramos perceber as nossas possibilidades de intervenção na sua estrutura.

A questão do sujeito é, então, decisiva. Ramos (2006), por exemplo, acredita - com base numa concepção lacaniana associada à abordagem dialética, que tem como categoria a questão da relação - que "o Eu humano se funda no Outro, por intermédio da linguagem" [sp]. Todo homem compõe a situação dada na medida em que existe, mas realiza-se através da ação (e do Discurso) no mundo social, que lhe é peculiar. Como constata o autor, trata-se da passagem da existência biológica para a existência humana.

Assim, a DHE repensa a ciência não só como análise estrutural, no contexto da observação metódica, controlada, mas também como projeto político ${ }^{5}$, no qual o cientista é ator engajado; combinando a noção de movimento da dialética marxista com a noção de estrutura social do estruturalismo, de modo que aplicaremos as categorias selecionadas a partir da contextualização do nosso objeto de análise, identificando

5 “[...] política no seu sentido profundo, como conjunto de relações humanas na sua estrutura real, social, no seu poder de construção do mundo" (BARTHES, 2001, p. 163). 
seus personagens e o palco sócio-histórico com o qual os textos produzidos por eles estão envolvidos. Mais do que isso, este método, combinado com a técnica semiológica, possibilita que observemos as singularidades das relações experimentadas neste lugar e as marcas que deixam no tecido social.

A DHE nos coloca, então, diante de uma tensão que povoa a história do humano, atravessada pelo Poder e pela ideologia; aliás, tensão essa produtora de um discurso que tem na Mídia o espaço privilegiado. Os textos publicados em páginas de periódicos, os telejornais, as ficções seriadas na televisão, os grandes portais da internet, o rádio, a publicidade estão impregnados pelo mito pequeno-burguês, com o objetivo de imobilizar o mundo e de garantir a manutenção dessa desigualdade. A proposta da DHE é, pois, explicar a realidade que se materializa no cotidiano, e é nesse sentido que a pesquisa semiológica se vincula a ela. Juntas, conseguem delinear as questões estruturais, respeitando sua complexidade, assim como revelar as singularidades das relações dialéticas, que deixam as suas marcas no tecido social. No estudo proposto, a DHE aparece cada vez que associamos o texto ao contexto e permitimos que dialoguem.

A problemática que nos mobiliza ao longo desta investigação se desdobra em inúmeras questões, particularmente ligadas às categorias de análise expressas da seguinte forma: como a lógica do "poder gerencialista" (GAULEJAC, 2007) se particulariza no discurso jornalístico? Como esse discurso trabalha ou não os estereótipos nos textos que os constituem? De que forma os mitos se articulam nesta fala?

Propondo tal investigação, não intencionamos imitar o leitor - o outro leitor, os muitos leitores que derivam no tempo e no espaço - nem mesmo encontrar o sentido final do discurso passado no tempo presente (porque não há um sentido oculto e/ou verdadeiro); mas nos desprendermos da história como contingência, da ideia de acaso, e, a partir do Jornalismo, significar (leitura como espaço de subjetividade) e/ou ressignificar (leitura como memória coletiva) a imagem das relações que o homem mantém em sociedade.

\section{Informações Sobre a Revista Você S/A}

A escolha da revista Você S/A para a realização deste trabalho se deve à combinação de algumas características relativa à referida publicação que foram mapeadas durante um estudo realizado por Wood Jr. e Paula (2002), voltado especialmente para sua linha editorial. De acordo com os pesquisadores, a revista possui um conteúdo atraente tanto a jovens aspirantes ao mercado de trabalho como aos veteranos que procuram complementar seu saber-fazer a fim de continuar competindo por uma vaga no mundo corporativo. Mais do que isso, o estudo revelou que sua grande aceitação pelo público leitor está relacionada à linha editorial de autoajuda adotada pela publicação, que informa ao profissional o que fazer para estar no mercado; são textos com prescrições de comportamentos.

Outro aspecto apontado por Wood Jr. e Paula (2002) refere-se ao fato de que a Você S/A é uma publicação representativa dos periódicos populares de gestão no Brasil, cuja linha editorial aborda temas como estratégias e oportunidades de crescimento profissional. O enfoque na administração da carreira (trajetória e qualificação) é indicado desde o título da revista, concebido como se o sujeito ("você") fosse empresa (S/A [sociedade anônima]).

Você S/A foi lançada em 1998, como extensão da revista Exame, que aborda o "mundo dos negócios". Seus editores perceberam que havia um acréscimo na venda da primeira quando esta apresentava matérias sobre as questões de carreira. Desta forma, decidiram criar um periódico específico para abordar o assunto. Foi assim que nasceu a Você S/A, considerada "instrumento de autoajuda em um contexto em que as pessoas buscam padrões de comportamento" pré-fabricados, conforme um dos editores em entrevista à Wood Jr. e Paula (2002), mas também traz explícita a concepção de "ciência gerencial", criticada por Gaulejac (2007) e assim descrita por Moraes (2012): "convida-se o indivíduo ao auto aperfeiçoamento incessante e ao gerenciamento racional de si mesmo como se ele próprio fosse uma empresa privada" (p. 287). Neste caso, o convite ao auto 
aperfeiçoamento está no discurso jornalístico em cada edição, e a concepção de indivíduo como empresa privada do tipo sociedade anônima (S/A) está impresso no título da revista: "Você S/A".

No processo de definição e desenvolvimento das pautas desta revista, ideias são colhidas em toda parte: revistas estrangeiras, livros, matérias de jornais, televisão ou em contato com consultores, empresários, trabalhadores e pesquisadores (WOOD JR. e PAULA, 2002). Esses auxiliam também na elaboração e redação de temas mais específicos, contribuindo no que se refere ao aspecto técnico da mesma forma que possibilitam o incremento nas vendas, principalmente quando são profissionais renomados, por seu status de especialista ou na condição de "grandes gurus".

De modo geral, a linguagem da Você S/A é informal, de caráter instrumental, com reportagens sintetizadas e de fácil assimilação. As matérias apresentam a "nova realidade empresarial" como imutável e desafiadora, demandando dos profissionais, a quem se dirige, a capacidade de adaptação e a necessidade de tornarem-se donos de seu próprio destino, como entidades autônomas. Nas matérias publicadas, predomina o culto da excelência e se incita a ser "o" melhor, transmitindo a ideia de que as empresas exigem excelência, uma noção de qualidade de trabalhador que Moraes (2012) considera uma "utopia de perfeição". Para tanto, a revista apresenta, em tom prescritivo, modelos de profissionais bem-sucedidos e apresenta em suas páginas palavras de ordem, chavões, clichês e slogans. Por exemplo: "como se defender do mal" e "mude suas atitudes em 2014" (edição n. 187); "como trabalhar com liberdade e assumir o controle de suas decisões" (edição n. 185); "como encontrar satisfação no trabalho" (edição n. 183); "seja o líder que as empresas querem" (edição n. 181); "como encantar as empresas" (edição n. 177).

Auxiliando a propagação das mensagens, o projeto gráfico privilegia a emissão de informações de maneira bastante acessível, através de tópicos numerados, boxes explicativos, testes, além de figuras e fotos quase sempre caricatas, bem-humoradas, para tornar simples aos leitores comportamentos complexos. De acordo com Friderichs (2010), trata-se de um tipo de estrutura narrativa que, se por um lado favorece a organização do relato dedicado ao leitor, uma vez que representa o real recortando-o e nominando-o, por outro também reduz a fragmentos o discurso a uma única palavra, um estereótipo (o título do box, o número que expressa a ordem de importância do passo tomado), negando a complexidade do conjunto de informações que compõem a reportagem ou seção, e sobretudo, dificultando o estabelecimento da relação de contiguidade que pode existir entre elas.

O público da revista, de acordo com uma pesquisa realizada pelo jornal Meio \& Mensagem (informações extraídas da página eletrônica da revista, sessão "quem somos"), é composto por meio milhão de profissionais, jovens executivos que possuem em média 35 anos, em igual proporção entre homens e mulheres. Muitos deles são bilíngues, interessados por tecnologia e pertencentes às classes A e B.

\section{Análise dos dados}

O discurso em questão, aqui posto como dilema "carreira e família", foi publicado na Você S/A do mês de maio de 2011, na editoria Agora, sessão Decisão Difícil (p.24). Ele se distribui por uma lauda inteira de número par (o que favorece a visibilidade dos textos, pois está a favor da direção linear da leitura à medida que o leitor avança pelas páginas da revista) e é composto por uma cartola (a que nomeia a sessão), um título (que não podemos aqui chamar de manchete, uma vez que não se trata exatamente de uma notícia), dois subtítulos, dois parágrafos de textos verbais e uma foto, que se localiza horizontalmente na folha, à esquerda, tomando-a em 2/3 de alto a baixo. Veja o aspecto visual da mesma na Figura 1. 
Figura 1

Editoria Agora, sessão “Decisão Difícil”

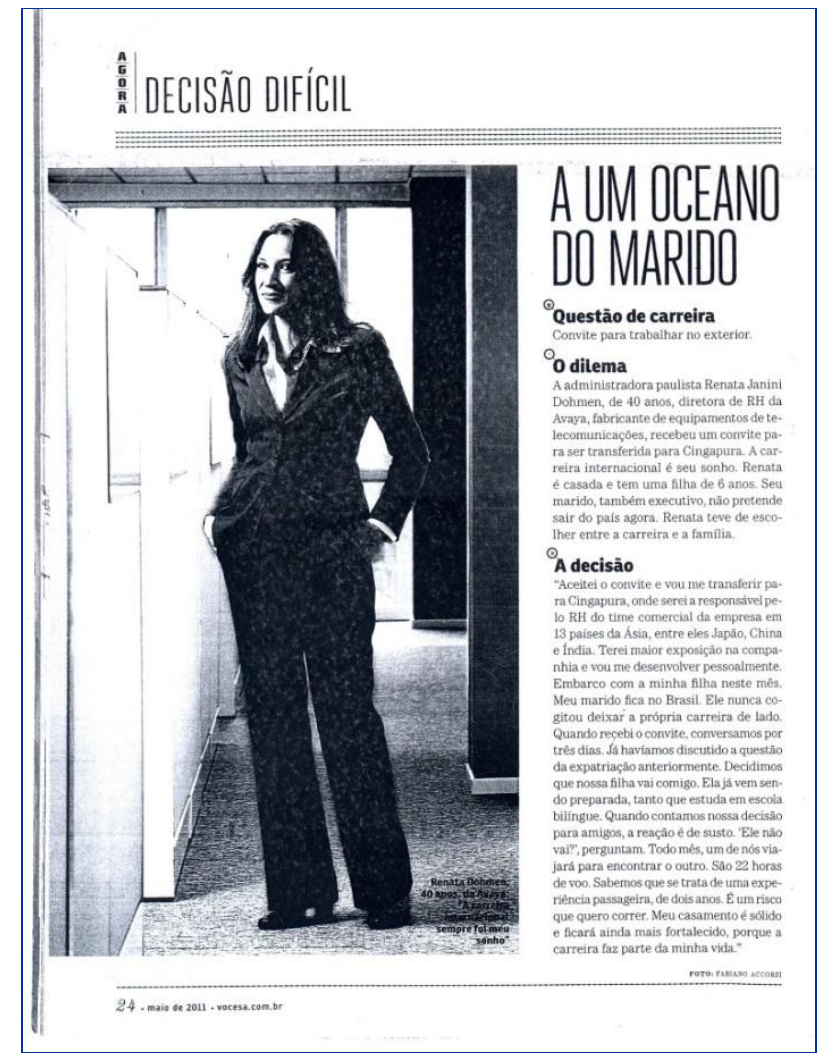

Fonte: Você S/A (2011, p. 24)

Essa rápida descrição de como o discurso está graficamente distribuído nas páginas da revista norteia nossa análise, já que ela evidencia a presença de uma diversidade de figuras de linguagem envolvidas por mais de um plano de expressão, assim como por uma série de marcas que indicam alguns trajetos de leitura possíveis. Para percorrê-los e/ou deixar-nos à deriva, desviando suas rotas aparentes, partimos da organização geral da narrativa (a disposição de seus elementos) e seguimos pelo eixo temático evidente (carreira versus família), dois aspectos que compõem o macramê da estrutura textual-e, com base na sua análise, tentamos aprofundar nossa leitura, respondendo, desse modo, à principal categoria de investigação proposta, o discurso (que é também, como veremos adiante, refém dos estereótipos e mitos que nas suas tramas se revelam e desvelam a lógica do poder gerencialista nele impresso).

Nesse sentido, percebemos de imediato o esforço da estrutura em direção à sua fragmentação (e, com ela, também das possibilidades de sentido), já que se trata de um parcelamento da informação. Dispersos e nominados (em três subtítulos e dois planos diferentes de expressão - verbal e não verbal), os blocos constituídos transformam-se em obstáculos à percepção de contiguidade do que está sendo dito. Assim, são unidades estruturais, no mais das vezes representadas por palavras, que se convertem em shifts de anúncio do mesmo discurso. No caso em análise, "questão de carreira", "dilema", "a decisão" (VOCE S/A, 2011, p. 24).

Os shifts parecem recortar o todo da realidade via nominação, quase sempre a estereotipando, como quem nega a complexidade pertinente a todo dado do real e, por conseguinte, viabiliza um vínculo descomprometido por parte do sujeito da enunciação com o acontecimento. Esparramados, esses textos, apesar de contemplar o mesmo tema, encerram-se em si próprios, resgatando e, especialmente, repetindo as 
informações, como se o fato fosse recriado em cada um dos itens. E, ao fragmentá-los, em idas e vindas, o relato assim organizado, desloca-os no tempo e no espaço, exigindo uma operação muito atenta e minuciosa do leitor, caso haja disposição em recompô-los.

A articulação, assim, se dá em torno de tópicos, como se cada um deles contivesse sua própria porção de <<verdade〉> e dispensasse o jogo dialético dos diferentes pedaços. Trata-se da conformação de uma estrutura que pressiona o signo, reprisando em cada trecho a mesma configuração ${ }^{6}$, até que seu sentido, ao ver-se, insistentemente preso à igual condição de assujeitamento, transforma-se em rótulo, estereótipo. É como se a imagem (palavra) evocasse naturalmente certo conceito.

Com esse pressuposto, percebemos com destaque a conotação possivelmente associada à palavra <<difícil >> (encontrada já no nome da sessão), estabelecendo uma ordem que enfatiza a relação de contiguidade com <<impossível>>e, do mesmo modo, a palavra <<decisão〉>, associada à ideia de <<exclusão〉>, ou algo de que Renata (profissional convidada pela editora da revista para ilustrar a reportagem) precisa abrir mão, mesmo que brevemente, possamos margear esta associação, uma vez que ela continuará sendo mãe e esposa.

Em outro momento do texto, o estereótipo também aparece, quando o discurso associa <<carreira internacional $>>$ e $<\langle$ trabalho no exterior $>>$ à impressão de $<\langle$ sucesso $\rangle$, e qualifica a opção de Renata, chamando-a de <<sonho〉>, relacionando-a à ideia de <<perfeição〉> e, por metonímia, de <<impossibilidade〉>, repetindo a parcimônia. É como se o jogo entre esses dois códigos os tornasse um só, com o mesmo sentido, a mesma indicação. Temos ainda a naturalização, pelo jogo das formas, da palavra <<executivo >>, ligando-a à situação de <<bem-sucedido)〉>, e <<bilíngue >>, relacionada à condição de bem-sucedido, apto a viajar, ou relativo a alguém que tem/sabe o suficiente para viver em outros países, para morar longe dos pais. Por isso, a semiologia barthesiana lembra que, durante a enunciação, o leitor, no ato em que se apropria da linguagem, sempre recolhe aquilo que se arrasta na língua, ou seja, os sentidos que a sociedade constrói e reproduz tão repetidamente, por meio dos signos, os quais acabam se cristalizando como sentidos inatos de determinados códigos ou conjunto de códigos.

Por fim, mas não menos relevante, observamos que este modo de fala sublinha uma relação de conflito (jogo de contrários), que se torna ainda mais robusto, quando o estereótipo da $\langle<$ carreira $\rangle$, rótulo daquilo que é prioritário, do mundo do trabalho, do limite da questão, associa-se ao estereótipo da $\langle<$ família $\rangle$, que aqui se revela como algo que atrapalha e que leva ao abandono do trabalho. A naturalização do significado é ativada pelo jogo entre as palavras "decisão", "difícil", "questão", "escolher" e "risco".

Para a semiologia, o estereótipo não é apenas o sentido cristalizado de um signo, que se produz e reproduz principalmente no espaço midiático, mas a evidência mais aguda do mito contemporâneo, cujo propósito é naturalizar determinada ideia e garantir que ela continue predominando por meio de uma representação coletiva. Para isso, o mito "prefere trabalhar com imagens pobres, incompletas, onde o sentido está diminuído, disponível para uma significação: caricaturas, pastiches, símbolos" (BARTHES, 2001, p. 148). Daí sua relação com os estereótipos.

Para podar os galhos da complexidade, o mito se constitui, de um modo geral, através da omissão da história e, neste caso, não apenas pela sua ausência (como se Renata, quem tem 40 anos e ocupa um cargo de gestão em uma empresa multinacional, nunca antes tivesse priorizado o trabalho ao invés da família), mas também pela distorção do futuro (como se viajar horas a fio, uma vez por mês, fosse uma boa solução para o conflito estabelecido, ou como se afastar a filha e a esposa do convívio cotidiano com o pai e marido apenas

${ }^{6}$ E não apenas neste texto, mas em outros tantos textos acessados pelo leitor em outras e diversas ocasiões. Esta pode ser apenas mais uma aparição da referida estrutura, num mundo dominado pela cultura gerencialista e, portanto, prenhe de documentos que reincidentemente a expressam. 
fortalecesse a relação). Com a omissão da história, não corremos o risco de nos depararmos com uma fábula não modelar, na qual não cabe o modelo (gerencialista) que conhecemos.

Outra figura do significante mítico encontrada no texto é a quantificação da qualidade, revelada e repetida nas frases: "time comercial da empresa em 13 países da Ásia", "conversamos por três dias", "Todo mês um viajará para encontrar o outro. São 22 horas de voo" e "sabemos que se trata de uma experiência passageira, de dois anos". Nessa estrutura, o número verbalizado procura adjetivar o acontecimento, dar-lhe uma medida de valoração: <<13 países >>, referendando status; <<uma vez por mês >>, como sinônimo de frequentemente, $<<22$ horas de voo $>>$, para qualificar o esforço em "nome da família". O ordinal, ou sua menção, surge então para validar a dimensão do discurso e nos ilude: <<só por dois anos〉>, sem apontar consequências.

Essa figura de linguagem, que vem seguida (ou seria acossada?) por outra: a constatação, cujo fundamento é o bom-senso - a opinião corrente de conformidade -, como se esta segunda forma mítica viesse para desculpar a dimensão das consequências exaltadas pela forma anterior: $<<$ a carreira internacional é meu sonho〉>, <<terei mais exposição na companhia e vou me desenvolver pessoalmente〉>. As figuras <<já havíamos discutido a questão anteriormente〉> e <<ela já vem sendo preparada〉> podem ser consideradas índices, indicativas de um movimento de interlocução que em tempo pondera e, finalmente, chega a uma conclusão. Ao serem retoricamente apresentadas, talvez construam a imagem de consignação da verdade, como uma evidência incontestável do real, coerente e consensual; "representa uma fala ativa, que pouco a pouco se converteu em fala reflexiva, mas de uma reflexão diminuída, reduzida a uma constatação" (BARTHES, 2001, p. 174).

Diante dessas revelações, entendemos onde, no discurso, está a dinâmica responsável por converter o ideológico em enunciação da obviedade, interditando apolissemia do signo e, consequentemente, a percepção do texto como espaço de realização da subjetividade. Ora, se tudo o que está dito já vem associado a um sentido imediato (sucesso versus sacrifício, trabalho versus família), a uma noção de verdade, e impregnado do "efeito do real", parece não restar muitos lugares nos quais o leitor pode construir significados seus, distinguir-se, questionar-se, não apenas no que diz respeito ao fato narrado, mas, sobretudo, acerca do seu lugar diante desse fato, do seu papel de intervenção na realidade dada, e, particularmente neste caso, das suas escolhas.

Aliás, tal efeito de realidade (como metonímia da verdade) também é reforçado por outras marcas discursivas, como a utilização da fotografia e o uso das aspas, ambas utilizadas para indiciar a personagem sobre a qual o discurso se mobiliza. A primeira delas anuncia o referente e "comprova" sua existência "de sucesso", uma vez que, mesmo diante da "decisão difícil", Renata revela-se "sorrindo". Já a segunda, aparentemente lhe dá voz (embora possivelmente se trate de uma fala escolhida por outrem que não ela mesma - sujeito assujeitado -, uma fala recortada).

Em qualquer tipo de texto, as aspas indicam, de imediato, uma entorse do discurso: ou para destacar determinado signo (embora elas mesmas sejam um, o do próprio deslocamento), ou para creditar certa intertextualidade, ou, ainda, para lhe abrir uma pausa de fluidez. No entanto, na estrutura do texto jornalístico, as aspas assumem um significado particular, além, é claro, da função de destaque. Seu trabalho no jogo da significação é avisar ao leitor, feito um shifter de anúncio, acerca da presença da fonte que compõe o relato, da fala do outro da qual o autor se apropria para compor a narrativa. Por isso, sua presença ao longo do texto é conotadora do real, confere credibilidade à informação, testemunha o relato publicado (como as falas literais de Renata que ancoram e/ou justificam a decisão tomada). Pela convenção, tudo que não estiver entre aspas e imediatamente após a menção não se converte em citação indireta, supõe-se relato objetivo. E, na suposta objetividade do texto jornalístico, também se esconde um "mostro", cerceador de sentidos.

Trata-se da opção recorrente pela estrutura informativa (em oposição à opinativa) que se manifesta, entre outros recursos, por meio da utilização da terceira pessoa do singular, que oculta o autor. Tal disposição 
conota um aparente distanciamento entre o jornalista (suposto artífice do texto), o fato ou personagem (dado da realidade), e o leitor (espectador do caso relatado), que guarda a negação de uma narrativa singular (contextualizada, ímpar) e promove, assim, sua naturalização, como se o fato e a própria percepção do fato tivessem uma sobrevida fora de qualquer linguagem; tal qual o mito tautológico, que, por força de autoridade (relacionada aqui à impressão de natureza), sentencia o leitor - como a mãe que diz ao filho ao repreendê-lo -, "é assim porque sim" (para ter sucesso profissional, é preciso fazer sacrifícios pessoais, e pronto!). A supressão dos signos enunciantes aparece, então, no relato, para significar a força deste referente, que, na ausência manifesta de um autor, parece falar por si próprio.

Para além dessa relação, o discurso pode guardar uma dialética ainda mais complexa, a da metáfora: $<<a$ um oceano do marido >>, que aqui mostrasse como uma ruptura na trança dos sentidos. De acordo com o estudo semiológico, a metáfora, de modo geral, cumpre uma tarefa fundamental na ruptura com o signo cristalizado. Barthes $(1988$, p. 83) diz que ela é uma via para o significante, pois permite nos descondicionarmos da finitude do sentido. "É ela que pode dar dispensa ao significado (como único)".

Por outro lado, por perverter a estrutura típica, o relato assim organizado talvez nos desarranje diante do texto e, com isso, permita perceber a infinitude de combinações por meio das quais é possível produzir significados. Para encontrar essas fissuras no Discurso, onde podemos estar em fruição, dependemos, porém, do reconhecimento da força do leitor em significar - com sua bagagem cultural, sua subjetividade - os signos oferecidos e as estruturas nas quais estão imersos, o que nos leva para o translinguístico. Diante de um leitor, cuja cultura ${ }^{7}$ (anterior a esta reprise) já se encontra atravessada pelo coro gerencialista, tal operação fica comprometida, uma vez que o dito (a relação inevitável entre sucesso profissional e sacrifício pessoal) apresenta-se apenas para corroborar uma noção já constatada, aparentemente óbvia e, portanto, para todos os efeitos, "verdadeira". E por isso dizemos que, diante do texto, o sujeito, que nele se realiza, pode tanto transformar quanto sustentar o cenário social com o qual está imbricado.

Ganhou destaque a abordagem escolhida pela revista no momento de prescrever a solução ao dilema carreira versus família. Aparentemente, nenhuma das alternativas encontradas (ou indicadas pelo texto) para os dilemas instalados é satisfatória; no entanto, muitas delas não são apresentadas como comportamentos de sacrifício, mas de investimento, uma vez que o resultado final é o sucesso do profissional e a resolução do conflito, ou a compreensão da família.

É sob esta perspectiva que se observa o cenário socioeconômico que propiciou a emergência desses dilemas, configurando-se como um período de intensa ansiedade e insegurança, afetando os trabalhadores de tal forma que eles se constituem como um forte mercado consumidor de publicações no estilo da revista analisada, cuja característica principal é buscar e suprir as incertezas e, ao mesmo tempo, oferecer uma espécie de autoajuda. Trata-se de uma narrativa acessada sob a tutela do sucesso, do heroísmo e da meritocracia, que muitas vezes apresenta um pacote de imposições escamoteadas pelos "finais felizes" e que persuadem o leitor pela via da cumplicidade.

Pelbart (2000, p. 26) apoia essa constatação dizendo que "vivemos todos aprisionados, prisioneiros a céu aberto. Isso se deve a várias razões, certamente à maneira como o capitalismo atual invadiu as esferas mais privadas e íntimas da vida humana, desde a fé até o corpo biológico. Não há mais exterior para o capital". As distâncias, outrora existentes entre esfera pública e privada, hoje são reduzidas a limites tênues, o que muitas vezes torna confuso o tempo que se destina a cada uma delas.

\footnotetext{
${ }^{7}$ Para Barthes (1981), nossa cultura é constituída por todos os textos que nos atravessam ao longo da vida. O fato é que os elementos da cultura, dispersos nos cenários sociais, estão presentes na maneira como falamos, na nossa sintaxe, no entrelaçado que fazemos dos signos, de modo que, como alerta o autor, "não podemos passar para o não discurso porque o não discurso não existe" (p.159).
} 
Assim, a subjetividade em produção, movida pela grande máquina capitalística, vai sendo moldada com a crença de que aquele que não dedicar muitas horas ao trabalho não será reconhecido; que aquele que não abrir mão de sua vida pessoal em prol da empresa não será recompensado. Dessa forma, aos poucos, a subjetividade dos indivíduos é produzida, ou forjada, com base no sistema de submissão dissimulado e, então, os trabalhadores tornam-se, cada vez mais, seres de fácil manipulação (GUATTARI e ROLNIK, 2005).

A reportagem reforça uma vida familiar aparentemente "resolvida". A executiva aparece explicitando as decisões e naturalmente adaptada ao novo contexto. A reportagem mostra elogiosamente a família que aceita e está empenhada para o sucesso da sua carreira proporcionada pelas empresas. Em geral, a editoria mostra a família e carreira bem-sucedidas, apesar dos dilemas enfrentados. Auxiliando a propagação dessa mensagem, o projeto gráfico emite informações caricaturais de uma executiva sorridente.

Mais uma vez, os conteúdos explicitados pela referida publicação revelam a ambiguidade da condição desse novo profissional: embora ele tenha o poder de decidir entre a família e o trabalho, seu poder está submetido, ou permanece sob a vigília daquilo que é prescrito pela reportagem, pela empresa à qual pertence e, em última análise, pelo mercado, como a decisão correta a ser tomada. Trata-se então de uma condição de assujeitamento, tal qual o nome da revista já indicia: "Você". Desse modo, apesar de o leitor ocupar um lugar de protagonismo, pois a revista é produzida em seu nome, ele não passa de um ventríloquo da ideologia gerencialista (GAULEJAC, 2007).

Aliás, a reportagem ilustra o que Gaulejac (2007) menciona sobre a sociedade se deixar contaminar por esta posição ideológica, que nasceu na esfera privada, mas se espalhou na esfera pública e em todos espaços organizacionais (cidades, organizações, família, relações amorosas, outros). Dessa forma, o modelo gerencialista se revela num dos veículos de literatura pop management brasileira. Para o autor, "nascida na esfera do privado", a ideologia gerencialista tende a se espalhar nos setores públicos e no mundo não comercial, assujeitando profissionais, alunos e por vezes docentes no que se refere a sua condução (carreira) na lógica de uma rentabilidade que recai sobre todos, inclusive sobre seus familiares. O poder gerencialista provoca a desorganização da vida familiar, de seus ritmos biológicos, das relações de afeto e da liberdade.

\section{Conclusões}

Após a análise, de modo geral, foi possível identificar que o caráter prescritivo do conteúdo apresentado por Você S/A se confirma, tal qual indiciava a revisão teórica realizada a priori. Mas, para além disso, e particularmente, também se observou que a principal oferta feita ao leitor manifesta-se através de uma série de receituários no que concerne à solução dos dilemas relativos às categorias de análise, cuja decisão de prioridade, de um lado, fica a cargo do empregado, e do outro, já está predeterminada pela condição de assujeitamento do mesmo em relação ao comportamento gerencialista. Não se constatou abertura para reflexões ou questionamentos. As críticas encontradas não transcendiam uma perspectiva dicotômica, tal como mensagens que se traduziam em "fatores de fracasso ou sucesso, indicadores positivos ou negativos" (GAULEJAC, 2007).

Também foi possível observar que a abordagem adotada pela revista, no que diz respeito ao binômio já destacado, propõe a supervalorização da aparência e do bom humor, em detrimento da revelação das dificuldades e dos sofrimentos que são genuínos ao processo de tomada de decisão pelo qual passa o profissional na construção de sua carreira. Por meio de mensagens simplificadas e, portanto, esvaziadas da complexidade de seu contexto, a reportagem analisada apresentou um modelo ideal de decisão; modelo este reconhecido pelas organizações e que, consequentemente, deve ser seguido pelo trabalhador. 
As representações do investimento do sujeito e da família na carreira reforçam o conceito do poder gerencialista que refere a sua condução (carreira) na lógica de uma rentabilidade sem precedentes. A desorganização da vida familiar, de seus ritmos biológicos, horários irregulares, e da liberdade, traduzindo-se em desregulamentação, são representações subliminares nas reportagens e que prescrevem um modo de ser e agir, deixando claro que a vida pessoal e familiar deve subordinar-se ao trabalho. Não há, portanto, reserva da intimidade da vida privada e familiar.

Trata-se de uma mídia que objetiva serializar e modelar trabalhadores de acordo com as necessidades do mercado e, portanto, disseminar valores como competitividade, falta de solidariedade, imprevisibilidade da vida e carreira, desapegar-se das coisas e pessoas.

Ao analisar tal editorial, verifica-se uma clareza quanto ao produto oferecido aos seus leitores e o resultado que é esperado obter dos mesmos. Por meio de mensagens claras, bastante objetivas e dicotômicas, o editorial analisado apresenta o modelo ideal de trabalhador considerado pelas organizações. No entanto, embora aparentemente simples, as mensagens distribuídas pela publicação também são desprovidas de complexidade, e, desse modo, produzem o efeito de natureza no artifício da cultura. Em outras palavras, isso significa dizer que tais conteúdos, ao serem reproduzidos em lugares e sob estruturas diferentes daquelas em que foram produzidos ou sugeridos para sua aplicação, acabam por consolidar estereótipos que serão assumidos pelo leitor como obviedades inquestionáveis, incorporados ao seu próprio discurso. Tais estereótipos conduzirão os profissionais a comportamentos imaginados como ideais para conduzir suas escolhas entre carreira e família, que, neste caso, correspondem à manutenção da ideologia gerencialista.

Os resultados do estudo revelam que a revista Você S/A traz uma noção predominante de que o modelo ideal consiste naquele que resolve mais facilmente os dilemas relativos à carreira e à família. Fato é que a revista traz representações de que problemas familiares não devem ser levados para as empresas. A revista, portanto, legitima a discussão de que família não é um problema nem da empresa, nem da esfera pública, mas sim unicamente do sujeito, na esfera privada, legitimado pelo modelo gerencialista.

Não há dúvidas de que a literatura pop management é um gênero construído por uma linguagem que nos permite compreender o mundo que nos rodeia; a realidade. Contudo, não nos conduz à autonomia, à produção da subjetividade consciente, mas ao aprisionamento pela estrutura linguística, à subjetividade inconsciente, a "relações líquidas", à fluidez. Assim, são construídos os fundamentos da gestão gerencialista na literatura pop management no tema carreira e família.

\section{Referências}

ARGYRIS, C.; SCHÖN, D. A. Organizational learning: a theory of action perspective. Reading: Addison-Wesley, 1978.

A UM OCEANO DO MARIDO. Você S/A, n. 155, maio, p. 24, 2011.

BARTHES, R. Ensaios críticos. Lisboa: Edições 70, 1971.

. Aula. Tradução de Leyla Perrone-Moisés. São Paulo: Cultrix, 1978.

O grão da voz. Lisboa: Edições 70, 1981.

O rumor da língua. São Paulo: Brasiliense, 1988.

Mitologias. Rio de Janeiro: Bertrand Brasil, 2001a. 
. A aventura semiológica. São Paulo: Martins Fontes, $2001 \mathrm{~b}$.

Elementos de semiologia. São Paulo: Cultrix, 2001c.

BAUMAN, Z. Modernidade líquida. Rio de Janeiro: Jorge Zahar, 2001.

Amor líquido. Rio de Janeiro: Jorge Zahar, 2004.

Vidas desperdiçadas. Rio de Janeiro: Jorge Zahar, 2005.

Vida líquida. Rio de Janeiro: Jorge Zahar, 2007a.

Tempos líquidos. Rio de Janeiro: Jorge Zahar, 2007b.

A arte da vida. Rio de Janeiro: Jorge Zahar, 2009.

BLEICHMAR, S. La construcción del sujeto ético. Buenos Aires: Paidós, 2008

CARVALHO, J. L. F.; CARVALHO, F. A. A.; BEZERRA, C. O monge, o executivo e o estudante ludibriado: uma análise empírica sobre leitura eficaz entre alunos de administração. Cad. EBAPE.BR, v. 8, n. 3, p. 535-549, set. 2010.

CHANLAT, J. F. Ciências sociais e management: reconciliando o econômico e o social. São Paulo: Atlas, 2000.

DEBORD, G. A sociedade do espetáculo: comentários sobre a sociedade do espetáculo. Rio de Janeiro: Contraponto, 1997.

ECCEL, C. S.; GRISCI, C. L. I.; TONON, L. Representações do corpo em uma revista de negócios. Psicologia \& Sociedade, v. 22, n. 2, 309-317, 2010.

FLACH, L. et al. Sofrimento psíquico no trabalho contemporâneo: analisando uma revista de negócios. Psicologia \& Sociedade, v. 21, n. 2, p. 193-202, 2009.

FREZZA, M.; GRISCI, C. L. I.; KESSLER, C. K. Tempo e espaço na contemporaneidade: uma análise a partir de uma revista popular de negócios. Revista de Administração Contemporânea, v. 13, n. 3, p. 487-503, 2009.

FRIDERICHS, B. P. Comunicação: discurso, fait divers e poder em O Nacional: uma abordagem dialética. Tese (Doutorado em Comunicação Social)- Pontifícia Universidade Católica do Rio Grande do Sul, Porto Alegre, 2010.

GAULEJAC, V. Gestão como doença social. São Paulo: Ideias e Letras, 2007.

GENRO FILHO, A. O segredo da pirâmide: para uma teoria marxista do jornalismo. Porto Alegre: Tchê, 1987.

GUATTARI, F.; ROLNIK, S. Micropolítica: cartografias do desejo. Petrópolis: Vozes, 2005.

HARVEY, D. Condição pós-moderna. São Paulo: Loyola, 2004.

ITUASSU, C. T.; TONELLI, M. J. Notas sobre o conceito de sucesso: sentidos e possíveis (re)significações. Revista de Administração Mackenzie, v. 13, n. 6, p. 197-224, 2012.

KELLNER, D. A cultura da mídia. São Paulo: EDUSC, 2001.

LAZZARATO, M.; NEGRI, A. Trabalho imaterial: formas de vida e produção de subjetividade. Rio de Janeiro: DP\&A, 2001.

MORAES, M. R. C. Resenha: Gestão como doença social: ideologia, poder gerencialista e fragmentação social. Revista Brasileira de Saúde Ocupacional, v. 37, n. 126, p. 287-289, 2012. 
OLTRAMARI, A. P. Dilemas relativos à carreira no contexto do trabalho imaterial bancário e suas repercussões nas relações familiares. 2010. 157 f. Tese (Doutorado em Administração)- Programa de Pós-Graduação em Administração. Escola de Administração. Universidade Federal do Rio Grande do Sul, Porto Alegre, 2010.

PAGÈS, M. et al. O poder das organizações. São Paulo: Atlas, 1993.

PELBART, P. P. A vertigem por um fio: políticas de subjetividade contemporânea. São Paulo: Iluminuras, 2000.

PUBLIABRIL. Perfil dos leitores. Você S/A. Disponível em:

<http://www.publiabril.com.br/marcas/vocesa/revista/informacoes-gerais>. Acesso em: 15 jul. 2013.

RAMOS, R. (Org.). Mídia, textos e contextos. Porto Alegre: EDIPUCRS, 2001. jul./dez. 2006

Análise de discurso: uma abordagem dialética. Conexão - Comunicação e Cultura, v. 5, n. 10, p. 217-233, Os sensacionalismos do sensacionalismo: uma leitura dos discursos midiáticos. Porto Alegre: Sulina, 2012.

SANTOS, W. S. F. et al. Carreira e sucesso em uma revista de negócios: uma análise à Luz da quantofrenia gerencialista. In: ENCONTRO DA ANPAD, 36, 2012, Rio de Janeiro. Anais..., Rio de Janeiro: Anpad, 2012.

SODRÉ, M. Antropológica do espelho. Petrópolis: Vozes, 2002.

STROGENSKI, P. J. R. Papel do sujeito nos estudos da linguagem. Revista de Letras, Curitiba, v. 6, 2003.

TIBURI, M. A. Olho de vidro: a televisão e o estado de exceção da imagem. Rio de Janeiro: Record, 2011.

VEEN, W.; VRAKKING, B. Homo zappiens: educando na era digital. Porto Alegre: Artmed, 2009.

VOCÊ AS. Perfil dos leitores. 2013. Disponível em:

http://www.publiabril.com.br/marcas/vocesa/revista/informacoes-gerais Acesso em 25/04/2013

WEBER, M. A ética protestante e o espírito capitalista. São Paulo: Companhia das Letras, 2004.

WOOD JR, T.; PAUlA, A. P. P. Pop-management: pesquisa sobre as revistas populares de gestão no Brasil. In: ENCONTRO DA ANPAD, 26, 2002, Salvador. Caderno de Resumos..., Salvador: Anpad, 2002. 